\title{
How I Reached the Age of 65 with a Congenital Heart Disease and Atherosclerosis
}

\author{
Delik D Gabaev
}

A.V. Zhirmunsky Institute of Marine Biology,

Far Eastern Branch of Russian Academy of Sciences, Palchevskogo Str. 17, 690041, Russia,

\begin{abstract}
$\underline{\text { Abstract: }}$
At me congenital disease of heart and the got atherosclerosis. In this publication I describe what mode of a life and what diet have helped me without medical assistance and medicines to live till 65 years and not to go on the old-age pension.
\end{abstract}

Keywords: Ventricular false chord; Atherosclerosis; Physical exercises; Diet.

The number of congenital heart diseases is rapidly growing in the United States; they require the most expensive treatment [1] and are often caused by external effects [2]. My parents were born far from each other and had different nationalities and therefore their three children may have had unusual birth defects. My sister was born in the amniotic membrane (shirt), my brother had the 33-th tooth and when I was already adult, a heart defect of my heart - a false chord in the left ventricle - was found. I was born in 1951 and I felt no discomfort to the heart for a long time; after school I did sports and even had local awards. Later, as a student, apart from the usual physical education lessons, I either swam with fins in the pool (4 times a week) $5 \mathrm{~km}$. per one training or practiced boxing. Suddenly, in the swimming pool I felt discomfort in the heart after my summer break. The heart test found a heart murmur but physicians thought these were the effects of active sports. However, after 8 years after the end of my sports career and sedentary life, the heart palpitations began to appear during the motion activity. For twenty years, I have kept my memory the fact that the Russian skater Yevgeny Grishin who had the congenital heart disease became the Olympic champion and I decided to eliminate the discomfort with the physical activity. Modern research has confirmed the beneficial effects of physical activity for the heart $[3,4]$.

In 1984, friends persuaded me to play soccer once a week and I became an active member of their team. First, the game seemed very difficult to me, as it was necessary to run for 90 minutes but then I got used and in addition to this game, I even started to do the easy physical exercises at home, and in the end of the 80s I started to work in my backyard. These exercises, as well as regular diving in the summer, led to the fact that in 1995 when I was 44 , my blood pressure was at $80 / 60$ and pulse rate did not exceed 40 beats per minute. This 11 year-physical activity allowed me to forget about my heart for another 15 years despite the stopping playing football and diving, and only the pressure rose to $120 / 80$ and heart rate increased to 60 beats per minute. Routine electrocardiogram tests did not detect any abnormalities and cardiologists established the following diagnosis - almost healthy. However, in 2000, when I was 49, an experienced physician focused on my heart murmurs and referred me to the echocardiography examination (echocardiography stress test). This method is widely used for the detection of heart diseases and it is easy to teach even the nonprofessionals [5]. In this examination, the fibrotic left ventricular false 
tendon (left ventricular false chord) (see Figure) was found in the left ventricle, and the doctors deduced an inference about the presence of atherosclerosis. The doctors did not offer treatment to me and I did not insist on it because I felt good.

However, in 3 years, in spite of the physical work once a week at my backyard, I started to feel discomfort in my heart again, and I resumed more difficult morning physical exercises. They lasted about 30 minutes the most difficult were the 108 demi plies and half push-ups in the same amount. I carry out one physical exercise for two days. In addition to these exercises, I have been having 30minute walks to work and back for six years, which sometimes turn into a run. Perhaps, my well-being may be positively influenced by my diet, concluding, apart from fruits, garlic as one of the main components (garlic has beneficial effect on blood vessels and the tone of the heart muscle [6]), and also by eating fish, seafood and vegetable oil for facilitating the slowing of progression of atherosclerosis [7]. All these activities have allowed me to once again forget about my heart and to reach the age of 65 without any doctors and medicines.

\section{References}

[1] Cedars AM, Burns S, Novak Eland, Amin AP (2016) Lesion-specific factors contributing to inhospital costs in adults with congenital heart disease. Amer J Cardiol pp: 1821-1825.

[2] Lucas A., Wakefield D., Bryant M., Chen H., Ambadapadi S. et al. (2016) Glycosaminoglycans (GAGs) in Cardiovascular Disease: Searching for the Sweet Spot. J Clin Exp Cargiol pp: 1.

[3] Wang L., Zhang N., Pan H., Wang Z., Cao $Z$ (2015) A combination of electroacupuncture and aerobic exercise improves cardiovascular function in patients with coronary heart disease. J Clin Exp Cardiol pp: 9.

[4] Garimella RS., Sears SF., Gahi AK (2016) Depression and Physical Inactivity as confounding the effect of jbesity on atrial fibrillation. Amer J Cardiol pp: 1760-1764.

[5] Beaton A., Nascimento BR., Diamantino AC., Pereira GTR, Lopes ELV et al. (2016) Efficacy of a standardized computer-based training curriculum to teach echocardiographic identification of rheumatic heart disease to nonexpert users. Amer J Cardiol pp: 1783-1789.

[6] Myaleshko I (2016) Two inexpensive of preparations. Medical messages pp: 20.

[7] Ajduković J (2015) the Role of NLRP3 Inflammasome in Cardiovascular Diseases. J Clin Exp Cardiol pp: 9.

The signature to figure: The fibrotic of false chord in left ventricle 